\title{
Rheology of Decane/Water and Triglyceride/Water Emulsions Stabilized by $\beta$-Casein and Sodium Caseinate
}

\author{
Eliane N. Figueiredo, ${ }^{a}$ José A. G. Arêas ${ }^{b}$ and Elizabeth P. G. Arêas*,a
}

${ }^{a}$ Instituto de Química, Universidade de São Paulo, Av. Prof. Lineu Prestes, 748, 05508-900 São Paulo-SP, Brazil

${ }^{b}$ Departamento de Nutrição, Faculdade de Saúde Pública, Universidade de São Paulo, Av. Dr. Arnaldo, 715, 01246-904 São Paulo-SP, Brazil

\begin{abstract}
Emulsões estabilizadas por $\beta$-caseína e sódio caseinato tiveram suas propriedades reológicas investigadas em função da natureza da fase oleosa, da força iônica e do pH. Fases oleosas de características estruturais distintas, a saber, decano e óleos vegetais de alto teor triglicerídico, foram ensaiadas. A emulsificação dos sistemas contendo decano foi significativamente mais efetiva do que aquela das amostras contendo triglicérides. Efeitos de pH e força iônica mostraram-se relativamente pouco importantes sobre a capacidade emulsificante da proteína. As propriedades reológicas foram marcadamente distintas em cada caso, com estruturas de caráter sólido $\left(G^{\prime}>G^{\prime \prime}\right)$ sendo produzidas com decano, diferentemente do que foi observado para amostras contendo triglicérides, nas quais a viscoelasticidade não foi nem mesmo aparente. A relevância de aspectos espaciais da estrutura da fase oleosa no desenvolvimento do caráter viscoelástico é discutida. Propõe-se que os fatores responsáveis pelo comportamento distinto observado residam possivelmente na interface gotícula/meio dispersante, inacessível por microscopia óptica, e guardam pouca relação com tamanho ou forma da gotícula.
\end{abstract}

$\beta$-Casein and sodium caseinate stabilized emulsions were produced and had their rheological properties investigated as a function of the nature of the oil phase, ionic strength and $\mathrm{pH}$. Oil phases of distinct structural characteristics, namely decane and vegetable oil of high triglyceride content, were assayed. The former was much more effectively emulsified than the latter. Effects of $\mathrm{pH}$ and ionic strength were minor. Emulsion rheological properties were strikingly distinct in each case, with viscoelastic, solid-like structures being formed with decane $\left(\mathrm{G}^{\prime}>>\mathrm{G}^{\prime \prime}\right)$, differently from what is observed for samples containing triglycerides as the oil phase, in which viscoelasticity was not even apparent. The relevance of the spatial features of the oil phase structure in the development of the emulsion viscoelastic character is discussed. Factors responding for the system distinct behaviour possibly reside at the emulsion droplet interface, unapproachable by optical microscopy, rather than on aspects related to particle size or shape.

Keywords: rheology, emulsion, $\beta$-casein, decane, triglyceride

\section{Introduction}

Milk is a complex fluid with remarkable nutritional properties. It is the first and most prominent feeding item in nursing and infant diet, also playing an important nutritional role in further stages of human life, where it is consumed both in natura and as an ingredient of various dairy products. In the latter, an adequate understanding of structuring properties and dynamical behaviour is usually required in order to allow the attainment and control of products with desired properties. ${ }^{1}$ In that context, understanding the

*e-mail: epgareas@usp.br physical chemical properties of milk and milk components can be decisive to achieve practical goals.

Caseins constitute the main emulsifying proteins of milk. ${ }^{2}$ These proteins comprise $c a .80 \%$ of milk protein fraction. A significant exposure of hydrophobic residues renders them rather insoluble in aqueous media. Their isoelectric $\mathrm{pH}$ is 4.6 and their molecular weight lies within a 19 to $25 \mathrm{kDa}$ range. A very relevant feature is their character of conjugated proteins with phosphate groups sterified to serines, which is an important aspect regarding their calcium binding properties. A peculiar micellar structure results from casein interactions with calcium, allowing highly insoluble calcium phosphate to 
be carried in the liquid form. ${ }^{3,4}$ That biochemical detail plays a most relevant physiological role, turning milk into a liquid nutrient. Micellar casein structures are also thought to play an important biochemical role, leading to the formation of a coagulum in the stomach that guarantees a more efficient nutrition.

High proline content and no disulfide bonds are structural features that contribute to casein adopting a less packed spatial conformation. That characteristic makes them less thermolabile than more tightly packed globular proteins. Their 3D structure and surface charge distribution are however still controversial in the literature..$^{5-7}$

Caseins comprise $\alpha, \beta$ and $\kappa$ fractions. $\beta$-casein, with 209 aminoacid residues (of which 35 prolines and no cysteine) and molecular mass of $24 \mathrm{kDa}$, has a particularly strong amphiphilic character, represented by a highly negatively charged $\mathrm{N}$-terminal due to the close location of the five serine phosphates and a hydrophobic C-terminal end. Such an amphiphilic character gives this protein an efficient surfactant role at the oil/water interface, effectively diminishing its interfacial tension. Molecular modelling clearly indicated the protein affinity for the interface, with the macromolecular dipole defining the protein orientation relative to the interface, eventually leading to a less extended conformation in a dielectrically discontinuous environment. ${ }^{6-8}$ These studies also confirmed the role of the phosphate group in the $\beta$-casein molecule with respect to its interfacial properties, as demonstrated experimentally. It has been reported that removal of the phosphate groups from whole casein reduces its ability to maintain emulsion integrity. ${ }^{9}$ An experimental study on the functional and interfacial properties of $\beta$-casein and dephosphorylated $\beta$-casein suggested that its mechanisms of emulsion stabilization depend on the charged phosphate groups. ${ }^{10}$ The serine phosphate residues, clustered in the $\mathrm{N}$-terminal region of the protein, account for the high net negative charge on this region and appear to be critical for $\beta$-casein emulsion stabilizing properties. ${ }^{11}$

Caseins are widely used in the form of surface active soluble caseinates that guarantee good stability to dairy products. Such a protective effect is partly due to their resistance to heat and capacity to incorporate water. Caseinates are non-micellar, more soluble forms of casein due to the presence of sodium counter ions at the phosphate groups. ${ }^{1}$ They are a non-homogeneous protein set, being constituted by all casein sub-fractions in the sodium salt form.

Understanding emulsification effectiveness and product stabilization in dairy items requires attention to the physico-chemical behaviour of the involved species.
Interfacial events are in the core of these issues, pervading an entire field of research where many fundamental questions are still open to investigation. Characteristics of the oil phase and that of the emulsifier are known to affect mechanical properties of the emulsions produced. ${ }^{12-14}$ However, specificities of each of the involved factors are not completely understood in detail. Limitations imposed by each of them become even more critical under conditions of shear. ${ }^{15,16}$ Moreover, issues related to sample stability and its relationship with emulsion morphology and sample composition have proved to be of relevance in various instances. ${ }^{17}$

In this work, a rheological study of emulsions formed by aqueous phases containing $\beta$-casein or sodium caseinate and oil phases represented by decane or vegetable (soya and sunflower) oil of high triglyceride content (>98\%) was undertaken. The effect of $\mathrm{pH}$, ionic strength, nature of lipid phase and protein on system emulsifying capacity and viscoelastic properties were investigated.

\section{Experimental}

\section{Sample preparation}

$\beta$-Casein and sodium caseinate were acquired from Sigma and decane was a Merck Schuchardt product ( $>95 \%$ purity). Edible sunflower and soy oil (Lisa trademark) were acquired in the local commerce. Ultra pure water (18 M $\Omega$, Milli-Q - Millipore) was used throughout. All other chemicals employed were analytical grade.

Emulsion samples were prepared by dispersion of a constant mass of protein $(0.015 \mathrm{~g}$ of $\beta$-casein or sodium caseinate) in $0.3 \mathrm{~mL}$ buffer solution followed by the gradual addition of small increments of the oil phase (decane or vegetable oil), under vigorous stirring in a blade homogeniser (Marconi). During stirring, flasks were periodically immersed in cold water, to avoid unwanted heating and possible protein denaturation. Final emulsion volumes varied according to emulsion distinct capacity to incorporate the oil phase (significantly higher for decane than for triglyceride, as shown ahead in the Results section). Thus, protein concentrations differ in the final preparations according to the nature of the oil phase (Table 1) and represent the minimum amount of protein needed in each case to guarantee complete oil incorporation. Mass weighing determinations were done for all samples in order to avoid misassessments of oil pippeting that could lead to erroneous concentration estimations. The aqueous nature of the continuous microphase was determined conductimetrically. 
Table 1. Sample composition and emulsion characteristics

\begin{tabular}{|c|c|c|c|c|c|c|c|}
\hline Sample & Oil phase & Protein & $\mathrm{pH}$ & $\begin{array}{l}\text { Ionic strength/ } \\
\left(\mathrm{mol} \mathrm{L}^{-1}\right)\end{array}$ & $\begin{array}{l}\text { Protein conc./(g\%) } \\
\text { in final emulsion }\end{array}$ & $\begin{array}{c}\text { Oil phase/aqueous } \\
\text { phase } /(\mathrm{m} / \mathrm{m})\end{array}$ & $\begin{array}{l}\text { Oil incorporation/ } \\
\text { (mg oil/mg protein) }\end{array}$ \\
\hline 1 & Sunflower oil & $\beta$-casein & 5.8 & 0.0 & 2.5 & 0.945 & 18.9 \\
\hline 2 & Sunflower oil & $\beta$-casein & 5.8 & 0.1 & 2.6 & 0.794 & 15.9 \\
\hline 3 & Sunflower oil & $\beta$-casein & 5.8 & 0.2 & 2.6 & 0.882 & 17.6 \\
\hline 4 & Sunflower oil & $\beta$-casein & 6.1 & 0.1 & 2.5 & 0.837 & 16.7 \\
\hline 5 & Sunflower oil & $\beta$-casein & 6.5 & 0.0 & 2.5 & 1.06 & 21.2 \\
\hline 6 & Sunflower oil & $\beta$-casein & 6.5 & 0.1 & 2.5 & 0.886 & 17.7 \\
\hline 7 & Sunflower oil & $\beta$-casein & 6.5 & 0.2 & 2.5 & 0.996 & 19.9 \\
\hline 8 & Sunflower oil & $\beta$-casein & 7.0 & 0.1 & 2.6 & 0.849 & 17.0 \\
\hline 9 & Decane & $\beta$-casein & 5.8 & 0.0 & 1.3 & 2.48 & 49.6 \\
\hline 10 & Decane & $\beta$-casein & 5.8 & 0.1 & 1.4 & 2.18 & 43.6 \\
\hline 11 & Decane & $\beta$-casein & 5.8 & 0.2 & 1.5 & 2.52 & 50.4 \\
\hline 12 & Decane & $\beta$-casein & 6.1 & 0.1 & 1.5 & 2.20 & 44.0 \\
\hline 13 & Decane & $\beta$-casein & 6.5 & 0.0 & 1.5 & 2.31 & 46.2 \\
\hline 14 & Decane & $\beta$-casein & 6.5 & 0.1 & 1.5 & 2.16 & 43.2 \\
\hline 15 & Decane & $\beta$-casein & 6.5 & 0.2 & 1.6 & 2.76 & 55.2 \\
\hline 16 & Decane & $\beta$-casein & 7.0 & 0.1 & 1.5 & 2.19 & 43.8 \\
\hline 17 & Soya oil & $\beta$-casein & 5.8 & 0.0 & 2.6 & 0.842 & 16.8 \\
\hline 18 & Soya oil & $\beta$-casein & 5.8 & 0.2 & 2.6 & 0.884 & 17.7 \\
\hline 19 & Soya oil & $\beta$-casein & 6.5 & 0.0 & 2.6 & 0.869 & 17.4 \\
\hline 20 & Soya oil & $\beta$-casein & 6.5 & 0.2 & 2.6 & 0.837 & 16.7 \\
\hline 21 & Decane & $\mathrm{Na}$-caseinate & 5.8 & 0.1 & 1.7 & 1.94 & 38.8 \\
\hline 22 & Decane & Na-caseinate & 6.1 & 0.1 & 1.6 & 2.14 & 42.8 \\
\hline 23 & Decane & $\mathrm{Na}$-caseinate & 6.5 & 0.1 & 1.8 & 1.74 & 34.8 \\
\hline 24 & Decane & $\mathrm{Na}$-caseinate & 7.0 & 0.1 & 1.6 & 2.18 & 43.6 \\
\hline
\end{tabular}

Rheological measurements: fundamentals and procedures

Rheological measurements employed an Anton Paar Physica MCR-300 instrument. Temperature of experiments was $20.00 \pm 0.01^{\circ} \mathrm{C}$, except in the activation energy assays, where temperatures in the range 0.00 to $25.00 \pm 0.01{ }^{\circ} \mathrm{C}$ were employed. All data were collected after sample thermal equilibrium was achieved. A cone and plate measurement device $\left(25 \mathrm{~mm}\right.$ diameter, $\left.1^{\circ}\right)$ was employed in the various experiments.

Experiments in stationary, oscillatory and transient flow regimes were performed..$^{18}$ Stationary measurements comprised flow curves and temperature tests, the latter aimed at the evaluation of flow activation energies. Flow curves were obtained by monitoring sample shear stress as a response to applied variable shear rate. Flow activation energies were measured from the temperature dependence of viscosity, applying the Arrhenius-like equation:

$\ln \eta=\ln K+E_{a} / R T$

For the dynamic (oscillatory) tests, a sinusoidal mechanical wave was applied on sample and its response was recorded in terms of the elastic (storage) and viscous (loss) moduli ( $G^{\prime}$ and $G^{\prime \prime}$, respectively), which are defined as:

$$
\begin{aligned}
& G^{\prime}=\frac{\tau_{0}}{\gamma_{0}} \times \cos \delta \\
& G^{\prime \prime}=\frac{\tau_{0}}{\gamma_{0}} \times \sin \delta
\end{aligned}
$$

where $\delta$ is the phase displacement angle between the oscillatory stress $(\tau)$ applied onto the sample and its strain $(\gamma)$ response.

The complex viscosity, $\eta^{*}$, was determined in dynamic (oscillatory) rheological experiments as a function of frequency. It comprises a real (dynamic or viscous) part, $\eta$ ', and an imaginary (elastic) part, $\eta "$, and is expressed as:

$\eta^{*} \equiv \eta^{\prime}-i \eta^{\prime}$

The dynamic tests consisted of amplitude and frequency scans. The former was relevant for the determination of the linear viscoelastic region (LVR), which defines the amplitude limits of the sinoidal wave for adequate application in the oscillatory tests. In stress amplitude tests, frequency was maintained constant at $1.0 \mathrm{~Hz}$. In frequency tests, the amplitude of the applied strain was always within the LVR limits. 
Relaxation experiments consisted of the application of a constant deformation onto the sample in the region of linear viscoelastic response, and in the simultaneous monitoring of the variations of sample internal stresses along deformation. Under such conditions, elastic solids are not expected to show any relaxation, whereas Newtonian liquids relax instantaneously and viscoelastic materials display a characteristic exponential decay, in order to maintain deformation constant. The presence of distinct populations responding for the complex rheological response can be assessed through the analysis of curve profiles, thus allowing relative contributions to be estimated.

Transient tests basically comprised creep tests, which consist of monitoring sample deformation in response to a constant stress within the limits of the linear viscoelastic region until attainment of a stationary flow, after which the application of the stress is discontinued. Sample recovery response is then monitored as a function of time. Creep curves are analysed in their characteristic phases (creep, stationary and recovery). Typical curve profiles are expected for a purely elastic, purely viscous, and for viscoelastic solids and liquids, thus allowing an estimation of distinct pure mechanical contributions in the samples assayed.

\section{Droplet morphology}

Emulsion samples were spread onto microscope slides and observed with an Olympus BX50 optical microscope, coupled to a digital camera (CoolSnap Pro, Media Cybernetics). Images were analysed with the Image Pro-Plus v.4.5.1.22 software, from Media Cybernetics. The latter, and the Origin v. 6.0 software (Microcal Software, Inc.), were employed in the statistical analysis of globule size distribution.

\section{Results and Discussion}

Table 1 presents emulsion (oil/water) sample compositions. Sodium caseinate or $\beta$-casein concentrations indicated correspond to the final protein concentrations of samples after oil incorporation was completed. The discrepancies observed reflect the distinct behaviour of the emulsions, with respect to effectiveness in oil emulsification. It is worth to note that differences in emulsification capacity are mainly related to the nature of the oil phase, and not to $\mathrm{pH}$ or ionic strength.

In fact, $\beta$-casein and $\mathrm{Na}$-caseinate were found to be able to emulsify considerably greater quantities of decane than of triglycerides (vegetable oils), for all $\mathrm{pH}$ and ionic strengths assayed (Figure 1). The decane oil phase appears to be more efficient in interacting with the aqueous phase when casein is present, as compared to the triglyceride-rich oils (sunflower or soy oils), leading to enhanced capacity of oil incorporation. Such interactions are likely to involve the hydrophobic domains of the casein molecules, in particular the hydrophobic terminal end of the $\beta$-casein fraction and the non-polar oil phase molecules. Effective triglyceride interactions with the casein molecules should be impaired by spatial constrictions represented both by the bulky volume of the triacylglycerol molecule and the additional spatial hindrance brought about by the cis double bonds of the fatty acid residues. That might hinder better emulsification, causing the overall capacity for oil emulsification to be comparatively diminished with the triglyceride as the oil phase, as compared to decane, in which such constrictions are not present. Thus, the distinct rheological characteristics observed for the two groups of emulsions might be related to differences in protein conformation at the decane/water and the triglyceride/water interfaces, leading to different protein adsorption abilities in the two kinds of interfacial microenvironments.

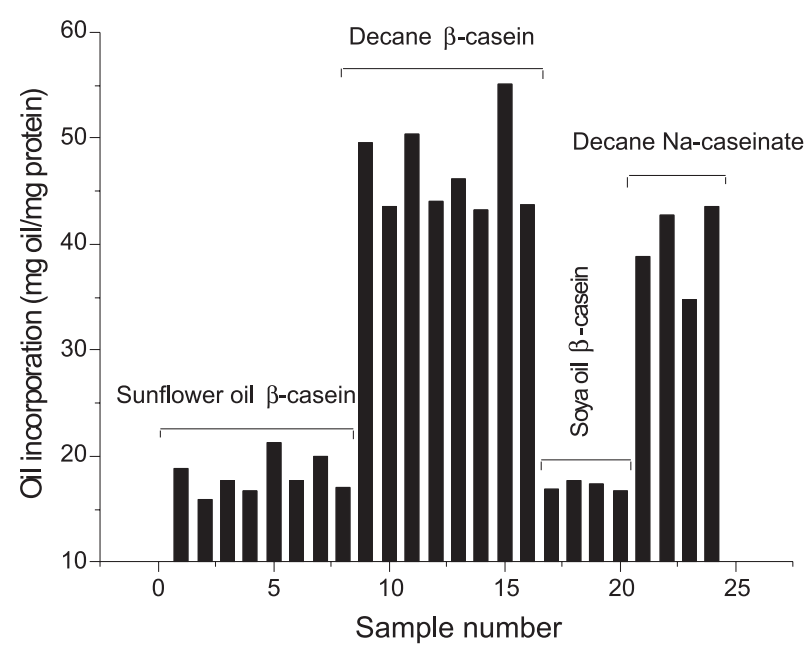

Figure 1. Emulsification capacity of $\beta$ casein and sodium caseinate for decane and triglyceride-rich vegetable oils (soya and sunflower).

Bylaite et al..$^{13}$ report that, for oil-in-water emulsions stabilized by both casein and phosphatidylcholine (PC) at low PC/casein molar ratios, considerably more $\beta$-casein is adsorbed at a hydrocarbon/water interface than at a triglyceride/water interface. That was ascribed to the differences in interfacial tensions between both interfaces. ${ }^{13,19}$ Quantitatively distinct affinities of protein (caseins) for the oil/water interface were described to vary according to the nature of the oil phase (hydrocarbon or triglyceride) and the presence of another surface active species in the preparation. ${ }^{13,20-22}$ Results seem to be very 
dependent on the surfactant/protein molar ratio, in such a way that a simple conclusion as to the sole affinity of the protein for the interface is not straightforward. ${ }^{13}$

In this work, we focused on the rheological behaviour of sodium caseinate and $\beta$-casein stabilized coarse emulsions (average droplet diameter size in the micrometer range), investigated within the limits of linear response. Some incursions into the less trivial non-linear regions of rheological behaviour of highly concentrated emulsions of food interest can be found in the literature. ${ }^{23}$ That will not however be approached here.

Figure 2 shows some typical flow curves obtained for $\beta$-casein/sunflower oil at different medium conditions. As should be apparent, flow is either very close to ideal (Newtonian), in the shear rate range applied, or slightly pseudoplastic, as in sample 7 ( $\beta$-casein/sunflower oil, $\mathrm{pH}$ 6.5 , ionic strength 0.2 ). Also, no consistent effect of $\mathrm{pH}$ and ionic strength on flow profile is observed.

Very distinct rheological behaviour was verified for decane/water emulsions stabilized either by $\beta$-casein or by sodium caseinate (Figure 3 ). These systems formed
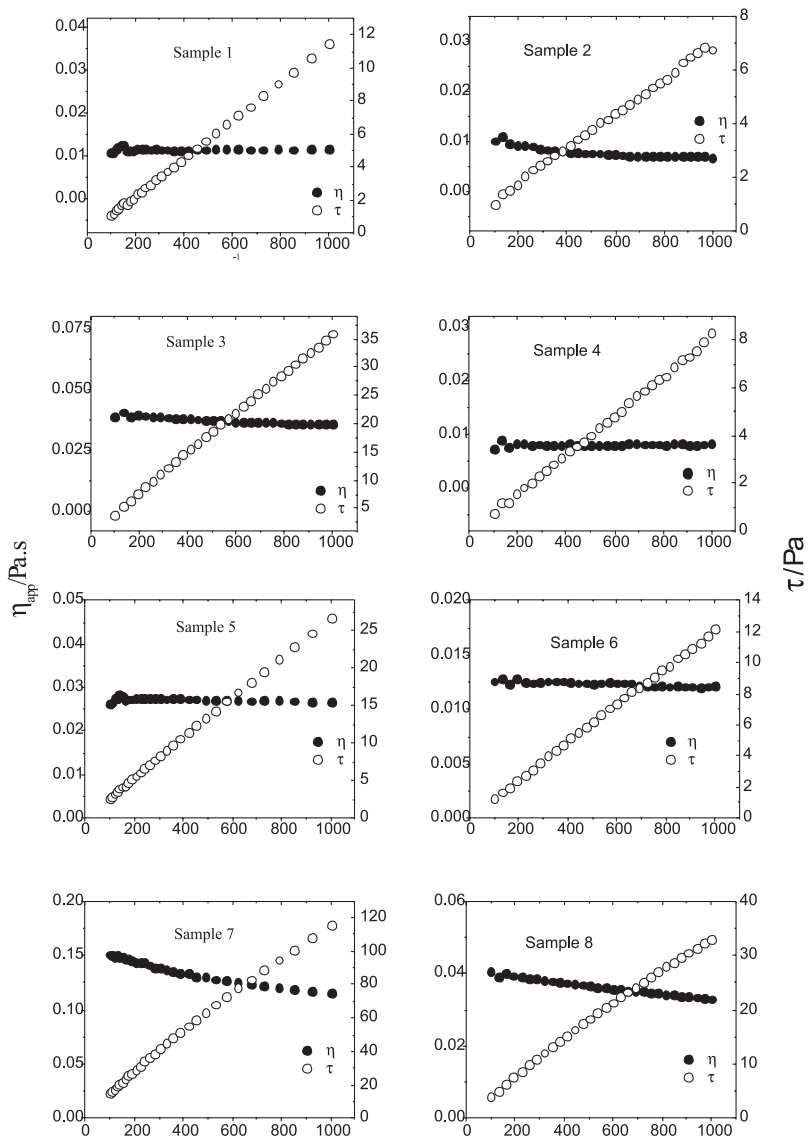

$(\mathrm{d} \gamma / \mathrm{dt}) / \mathrm{s}^{-1}$

Figure 2. Flow curves (shear stress versus shear rate) and viscosity dependence on shear rate for samples containing sunflower oil and $\beta$-casein (samples 1 to 8 , Table 1). solid-like structures of very distinct appearance from that observed for the triglyceride/water casein stabilized emulsions shown in Figure 2 and Figure 4 (first 4 graphs). Their flow curves were markedly pseudoplastic (Figure 3 and last 4 graphs in Figure 4). They were characterised by intense viscoelastic character, which was investigated by means of transient and oscillatory tests, presented further ahead in this paper. No significant dependence of viscosity on time (thixotropy or rheopexy) was observed for any of the samples assayed (results not shown).

Flow activation energies were determined as indicated in the Experimental Section. Typical graphs obtained from a temperature test for one of the samples is depicted in Figure 5. Results (Table 2) were within the range of characteristic values for non-covalent, transient interactions, such as hydrogen bonding $\left(\mathrm{ca} .20 \mathrm{~kJ} \mathrm{~mol}^{-1}\right)$ and are compatible with the simultaneous occurrence of van der Waals interactions, typically one order of magnitude lower than that. Although the figures obtained do not permit a distinction between the different kinds of emulsions relative to their inner structural features, they do however confirm the transient character of
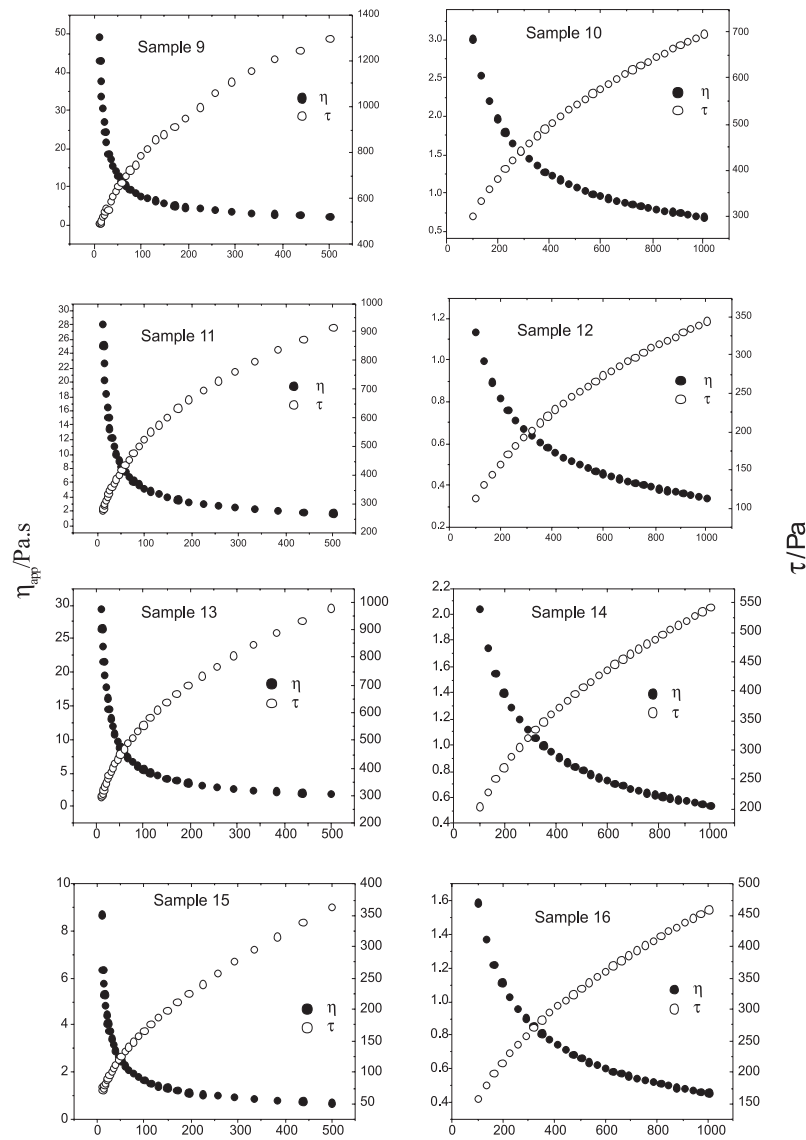

$(\mathrm{d} \gamma / \mathrm{dt}) / \mathrm{s}^{-1}$

Figure 3. Flow curves (shear stress versus shear rate) and viscosity dependence on shear rate for samples containing decane and $\beta$-casein (samples 9 to 16 , Table 1). 

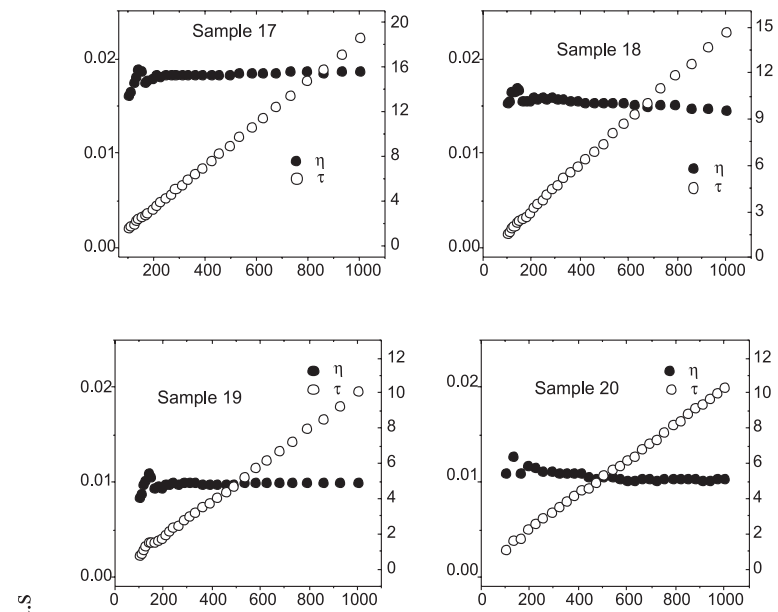

हैं
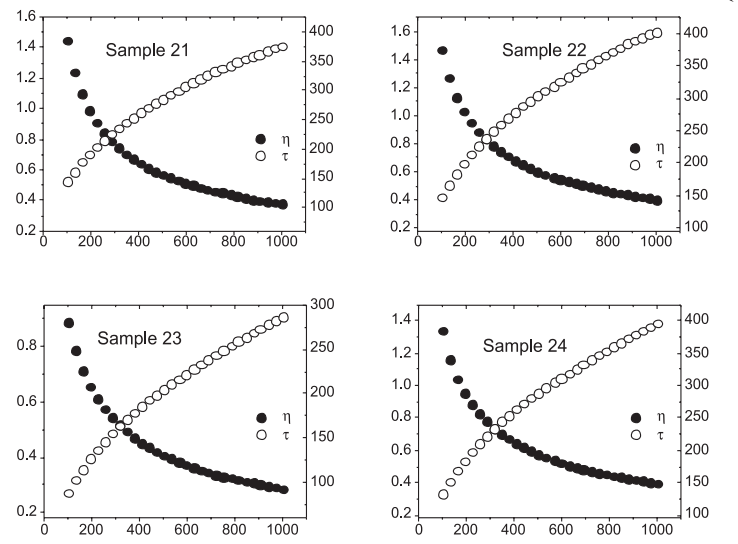

$(\mathrm{d} \gamma / \mathrm{dt}) / \mathrm{s}^{-1}$

Figure 4. Flow curves (shear stress versus shear rate) and viscosity dependence on shear rate for samples containing: soya oil and $\beta$-casein (samples 17 to 20, Table 1); decane and sodium caseinate (samples 21 to 24 , Table 1).

interdroplet interaction in all cases. It is interesting to note that in the oscillatory tests, rheological characteristics were very distinct between decane-containing and triglyceridecontaining emulsions (see Figures 6 to 9). However, results indicate that these very significant rheological distinctions do not correlate to differences in flow activation energies. It should be noted that oscillatory tests were strictly applied within the linear viscoelastic region, i.e., within the limits in which the gel structure is maintained. Flow curves as a function of temperature, from which flow activation energies were calculated, do not impose such limits but rather lead systems to a stationary flow regime, where the linear response regime may be exceeded. That leads us necessarily to consider the occurrence of at least two kinds of cohesive interparticle forces in the systems investigated: an "external", non-specific one, related to emulsion interdroplet interactions, which can be overcome by flow and whose values are reflected in $E_{a}$, and another related to "internal" droplet interactions, characteristically system-dependent and reflected in the very distinct system response in the oscillatory tests. The rather dispersive, although consistent in terms of order of magnitude, pattern of values obtained for $E_{a}$ (Table 2) thus reflect both $E_{a}$ non-sensitiveness to sample composition and the transient character of interdroplet interactions.

$\beta$-Casein was much more effective than sodium caseinate for emulsifying decane, as far as emulsion structural characteristics are concerned. Significantly more structured emulsions were generated when $\beta$-casein was employed as the sole emulsifier. In caseinate, a set of protein sub-fractions with distinct emulsifying capacities is present, including

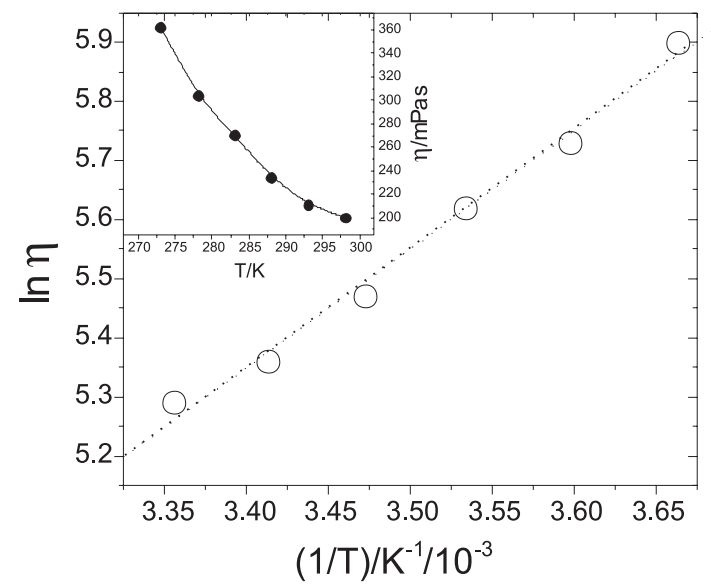

Figure 5. Dependence of $\ln$ of apparent viscosity on the reciprocal of absolute temperature for a casein emulsion. Inset: Typical response of casein emulsion to temperature variation (shear rate kept constant at $\left.500 \mathrm{~s}^{-1}\right)$.
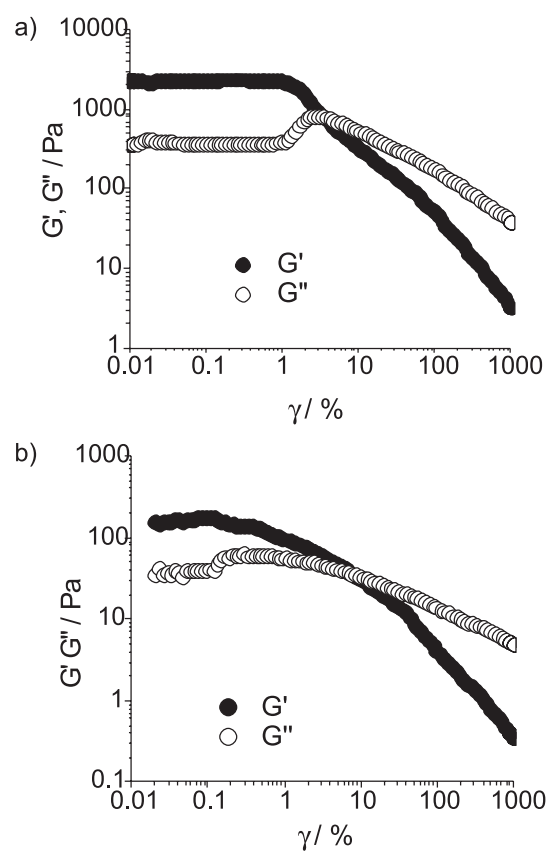

Figure 6. Storage and loss moduli variation with strain deformation for: a) sample 11 (decane and $\beta$-casein); b) sample 23 (decane and sodium caseinate), Table 1 . 

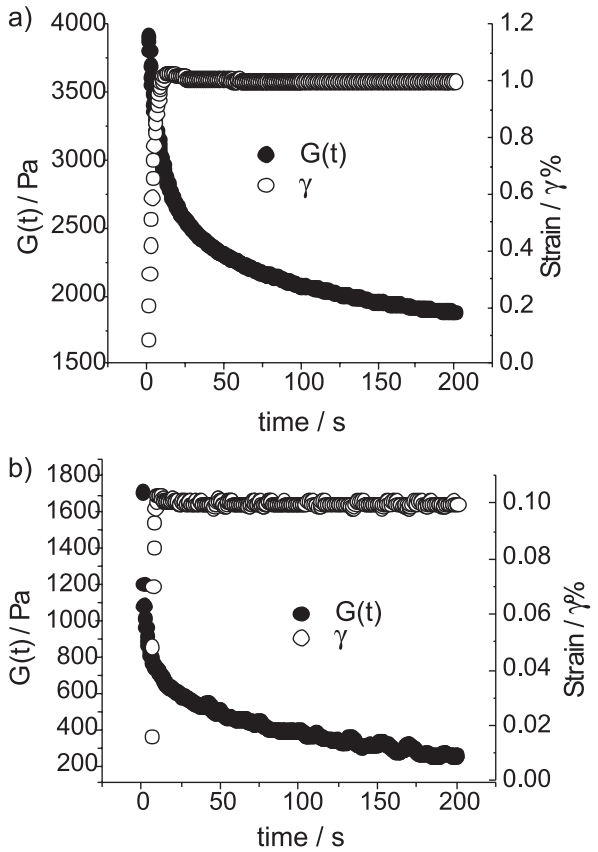

Figure 7. Variation of $G(t)$ as a function of time: a) sample 9 (Table 1), containing decane and $\beta$-casein; b) sample 23 (Table 1), containing decane and sodium caseinate.
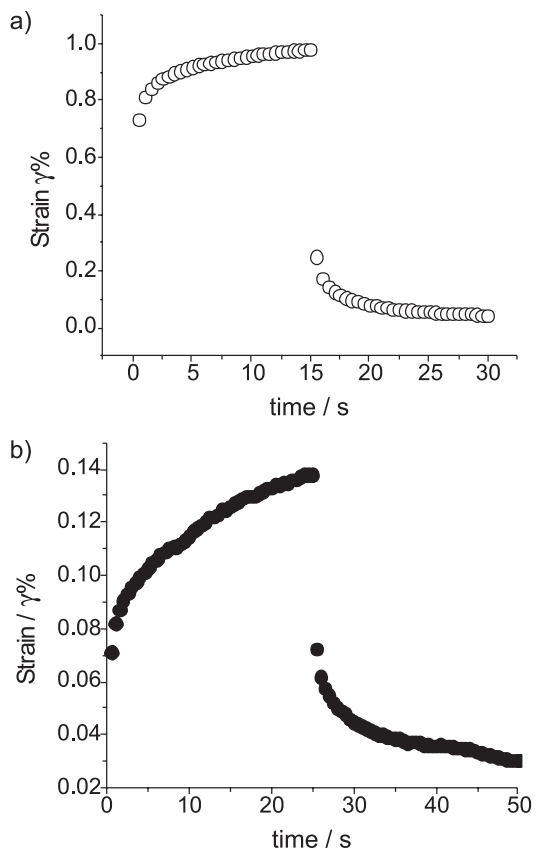

Figure 8. Creep test: a) sample 13 (Table 1), containing decane and $\beta$-casein; b) sample 23 (Table 1), containing decane and sodium caseinate

fraction $\beta$, which is well known for its intense emulsifying power. Considering that $\beta$-casein in caseinate is simply one among a set of various other proteins, a decrease in emulsifying capacity should be expected, on the basis of a reduction in its concentration. However, it is important to note that emulsification capacity is not likely to be a simple linear function of protein composition, but rather to depend
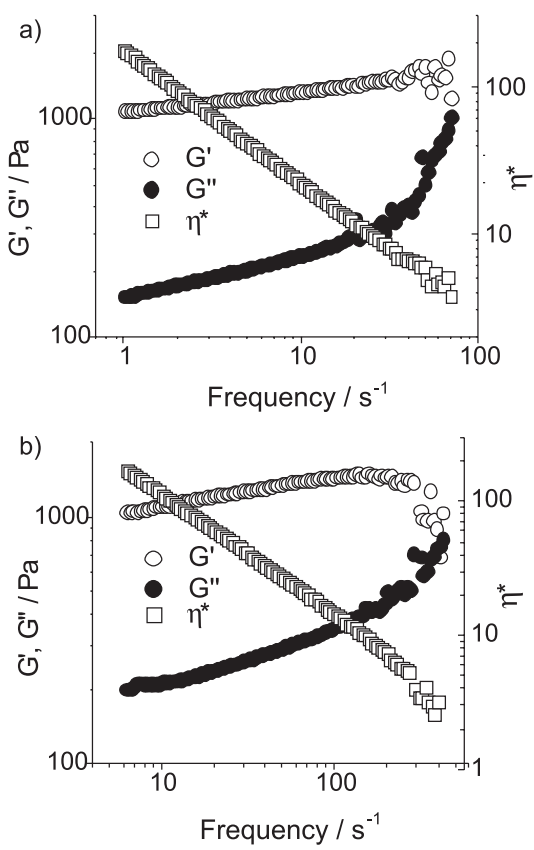

Figure 9. Dependence of storage and loss moduli and complex viscosity on frequency: a) sample 15 (Table 1), containing decane and $\beta$-casein; b) sample 23 (Table 1), containing decane and sodium caseinate.

on mutual interrelationship between protein components and that with the interface. Different aspects might play a role in that respect. Rampon et al., ${ }^{12}$ for instance, reports that the nature of the apolar phase has an impact on bovine serum albumin conformation when this protein is used as an emulsifier. They found that an apolar phase represented by a hydrocarbon induces far greater changes in protein (BSA) conformation, as inferred from tryptophan microenvironment in fluorescent experiments, than triglyceride oil phase does. Changes in protein conformation may result in differences in protein functional properties, such as emulsifying capacity. We reckon that casein-decane and casein-triglyceride interfacial tensions play an important role in casein adsorption to the emulsion globule and should therefore influence rheological patterns of behaviour. However, as these data are not available, speculation on these effects should not be extended any further for the moment.

A significantly more extensive linear viscoelastic region (greater $\gamma$ ) was observed for $\beta$-casein/decane as compared to sodium caseinate/decane (Figure 6, Table 2). That indicates a structure that is able to stand relatively more intense deformation without rupture of its internal structure. Also, considerably larger (one order of magnitude) storage and loss moduli ( $G^{\prime}$ and $G^{\prime}$ ) were verified for $\beta$-casein/ decane emulsions as compared to sodium caseinate/decane (Figure 6). That indicates a significantly higher level of internal structuring in the former.

The occurrence of two dynamic populations in the emulsions was revealed from the analysis of the relaxation 
Table 2. Casein emulsion rheological parameters

\begin{tabular}{|c|c|c|c|c|c|c|}
\hline Sample & $E_{a}^{*} /\left(\mathrm{kJ} \mathrm{mol}^{-1}\right)$ & $t_{r I}^{*} /(\mathrm{s})$ & $t_{r 2} * /(\mathrm{s})$ & $\gamma^{* /(\%)}$ & $J_{e} /(\%)$ & $J_{v} /(\%)$ \\
\hline 1 & 21.95 & - & - & - & - & - \\
\hline 2 & 25.78 & - & - & - & - & - \\
\hline 3 & 20.28 & - & - & - & - & - \\
\hline 4 & 20.18 & - & - & - & - & - \\
\hline 5 & 18.42 & - & - & - & - & - \\
\hline 6 & 27.27 & - & - & - & - & - \\
\hline 7 & 21.35 & - & - & - & - & - \\
\hline 8 & 30.72 & - & - & - & - & - \\
\hline 9 & 10.58 & 11.0 & 101 & 1.36 & 92.73 & 7.27 \\
\hline 10 & 18.03 & 1.40 & 37.1 & 1.18 & - & - \\
\hline 11 & 14.78 & 9.20 & 63.8 & 1.06 & 92.61 & 7.39 \\
\hline 12 & 23.28 & 2.31 & 66.0 & 0.37 & - & - \\
\hline 13 & 14.87 & 7.00 & 109 & 2.77 & 95.34 & 4.66 \\
\hline 14 & 20.73 & 1.83 & 61.0 & 0.65 & 90.18 & 9.82 \\
\hline 15 & 16.93 & 11.0 & 60.0 & 0.40 & 100 & 0 \\
\hline 16 & 30.62 & 0.20 & 2.87 & 0.50 & - & - \\
\hline 17 & - & - & - & - & - & - \\
\hline 18 & - & - & - & - & - & - \\
\hline 19 & - & - & - & - & - & - \\
\hline 20 & - & - & - & - & - & - \\
\hline 21 & 23.18 & 6.0 & - & 0.042 & 82.94 & 17.06 \\
\hline 22 & 24.15 & 0.3 & 36.0 & 0.390 & 71.97 & 28.03 \\
\hline 23 & 24.10 & 24 & 34.2 & 0.180 & 72.88 & 27.12 \\
\hline 24 & 22.82 & 1.6 & - & 0.415 & 77.95 & 22.05 \\
\hline
\end{tabular}

curves (Figure 7) obtained for $\beta$-casein and sodium caseinate emulsion samples, where two groups of relaxation times, at least one order of magnitude distinct from each other, were observed. The possible occurrence of distinct aggregated species under flow would be consistent with such a dynamic behaviour. Thus, emulsions seem to comprise a non-homogeneous complex system not only under a morphological point of view, but also within a mechanical perspective.

The effect of salt or $\mathrm{pH}$ on relaxation times was not apparent. Nevertheless, it is interesting to note that highest relaxation times verified in the less mobile group $\left(\mathrm{t}_{\mathrm{r} 2}\right)$ referred to samples in the absence of salt (Table 1), which would suggest some hindrance for the mobility of systems when charges were not screened That coincides with the occurrence of a most extensive linear viscoelastic region, particularly at pH 6.5 (sample 13, Table 2). Results, however, were rather dispersive and cannot be conclusive at this point. As a general trend, higher relaxation times in the less mobile populational group were obtained for $\beta$-casein stabilized emulsions as compared to caseinatestabilized ones. It should be noted that the range of absolute values for $G(t)$ is quite distinct in each case (Figure 7), with higher figures being verified for the emulsion with $\beta$-casein as compared to that with sodium caseinate. These results are in accordance with what would be expected for more structured systems.

In a previous work, ${ }^{24}$ low resolution spin-spin $\left(T_{2}\right)$ relaxation times were determined for a $\beta$-casein/decane sample, and a more complex set of dynamic populations was reckoned to be present. By a selective deuteration procedure, it was possible to make a differential assignment of them. However, it is important to bear in mind that microscopic relaxation, such as that probed by NMR relaxation, does not necessarily match macroscopic mobility in systems under flow, as obtained from a rheological approach.

Creep curves (Figure 8) were obtained with the aim of assessing the elastic and viscous contributions to the mechanical behaviour of samples. The tests were restricted to the investigation of $\beta$-casein/decane and sodium caseinate/decane, since $\beta$-casein/triglyceride or caseinate/ triglyceride samples have not presented any appreciable viscoelastic character. Elastic and viscous compliances ( $J_{e}$ and $J_{v}$, respectively) were determined from the creep curves shown in Figure 8. The creep curve profile in Figure $8 \mathrm{a}$ shows the response of a $\beta$-casein/decane emulsion. A very significant elastic contribution is apparent, with a steep increase in sample deformation being observed as a function of time after application of the stress force, and a rather fast return to zero deformation when tension is removed 
after the achievement of the stationary regime of flow. On the other hand, creep curve profile obtained for sodiumcaseinate/decane is very typical of a viscoelastic system with a comparatively diminished elastic character.

The percent contributions of the elastic and viscous compliances calculated from the creep curve profiles are indicated in Table 2. Average $J_{e}$ values were $94.2 \%$ and $76.4 \%$ for $\beta$-casein/decane and sodium caseinate/decane, respectively. Sample 15 (Table 1) displayed a creep behaviour that was typical of a perfectly elastic solid, with $100 \%$ of elastic compliance. No appreciable effects of salt or $\mathrm{pH}$ were verified for the various samples assayed.

The dependence of the storage and loss moduli $\left(G^{\prime}\right.$ and $\left.G^{\prime}\right)$ and of complex viscosity $\left(\eta^{*}\right)$ on frequency, for emulsions containing decane and $\beta$-casein and decane and sodium caseinate, is displayed in Figure 9. It can be observed that curve profiles share similar contours for both emulsion samples, with $G^{\prime}$ consistently showing higher values than $G^{\prime \prime}$ throughout the frequency range. $\log G^{\prime}$ does not show a strong dependence on frequency, rather displaying a slight increase as frequency gets higher. That is suggestive of a well-organised, cohesive structure, probably well maintained by inter-droplets contacts, in agreement with indications from the strain amplitude and creep test results (Figures 6, 8 and Table 2). The monotonic $G^{\prime}$ and $G^{\prime \prime}$ broad curve profiles of Figures 9 a, b are compatible with the general character of samples assayed, i.e., rather heterogeneous, large-size particle samples. In Figure 9a, such a behaviour can be observed up to $c a .50 \mathrm{~s}^{-1}$, when the $G^{\prime}$ plateau starts to get unstable and begins to drop, whereas $G^{\prime \prime}$ starts to rise, indicating the destruction of the internal structure of the sample, in this case a decane/water emulsion stabilized by $\beta$-casein. For a similar emulsion stabilized by sodium caseinate, (Figure 9b), G' drops quite steeply at a considerably higher frequency $\left(c a .200 \mathrm{~s}^{-1}\right)$. This region of high frequency is known to reflect artifacts due to sample inertia effects and should therefore be treated accordingly. However, the fact that for the sample containing caseinate such inertia effects only start to appear at a considerably higher frequency than for a $\beta$-casein-containing sample reflects structural and dynamic distinctions between the two samples. On the basis of these considerations, it appears that the decane- $\beta$-casein emulsion, although more resilient to deformation as expressed by a significantly larger limit of the linear viscoelastic region (see Figure 6), is apparently more prone to a dynamic destabilization than decane-sodium caseinate emulsion. That can be understood considering that $\beta$-casein, being an isolated, homogeneous protein component, confers the emulsion a comparatively more regular, less complex structural character; which would cause the emulsion to respond less efficiently at higher frequencies due to the lower internal resistance of a regular structure to the sinoidal perturbation. Sodium caseinate, on the other hand, contributes with a more diverse heterogeneous set of protein components as compared to $\beta$-casein. That would possibly favour a more complex and dynamically more resistant protein intermingled network at the interface between the protein and the emulsion microphases.

Such effects on the flow profiles of $\beta$-casein or caseinate-stabilised emulsions should involve van der Waals interactions between the apolar domains of the casein molecules, which are supposed to protrude into the oil phase, and the oil phase. It has been reported in the literature ${ }^{12}$ that the nature of the oil phase can actually affect the structure of the emulsifier protein in emulsions stabilized by bovine serum albumin. In the present work, the strikingly distinct flow behaviour and rheological characteristics between decane/water and triglyceride/ water, emulsified either by $\beta$-casein or sodium caseinate, seem to reflect a similar occurrence. The small effect of $\mathrm{pH}$ on emulsion viscosity could possibly involve some subtle protein conformational change at the interface. Such changes would be likely to involve the phosphoserine residues, a site amenable to undergo changes as a function of $\mathrm{pH}$. Hindrance to mobility as a consequence of partial screening of charges could respond for increased viscosity. However, these effects were found to be minor.

Optical micrographies obtained for two samples bearing the most discrepant rheological behaviour, as indicated by their elastic compliance component $\left(J_{e}\right)$ values (samples 2 and 15), are shown in Figures 10a and 10b, respectively. Several fields of each sample were observed and analyzed. Sample 2 (sunflower) globule average size was found to be $6.6 \pm 5.4 \mu \mathrm{m}$ and that for sample 15 (decane) was found to be $6.3 \pm 3.3 \mu \mathrm{m}$. Emulsion droplet diameter size distributions of these two samples were also obtained (Figures 10c and 10d). Careful handling of the samples was adopted throughout the procedures so as not to affect the globule original morphology when emulsions were spread onto the microcopy slides. It should be noted that different pressures exerted on the slides in the course of microscopic procedures can significantly affect globule apparent size and size distribution. Results indicated that morphological features were similar within the limits of experimental uncertainty. As far as optical microscopy is concerned, no clear correlation between sample microscopic features (globule size and size distribution) and rheological characteristics could be established. It appears that for systems studied in this work other aspects, likely to be related to interfacial protein-lipid interactions, override size or shape aspects in responding for emulsion 

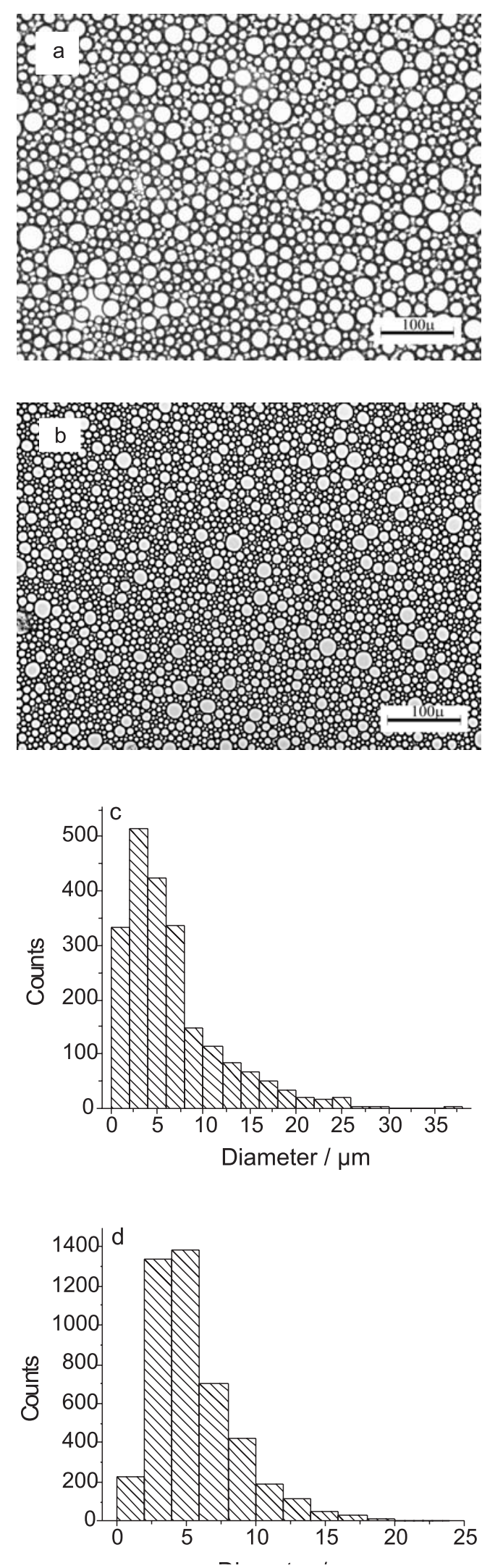

Figure 10. a) Optical microscopic image of sample 2 (a sunflower- $\beta$-casein emulsion); b) Optical microscopic image of sample 15 (a decane- $\beta$-casein emulsion); c) Globule diameter distribution of sample 2; d) Globule diameter distribution of sample 15 . morphological and mechanical characteristics. We assume that subtle distinctions, present at the emulsion droplet interface and unapproachable by optical microscopy, may have a major role in accounting for the discrepant emulsion functional characteristics and rheological behaviour observed, rather than aspects related to general particle size, distribution or shape.

\section{Conclusions}

Decane was much more effectively emulsified in water by $\beta$-casein or sodium caseinate than the triglyceriderich vegetable oils investigated. That was ascribed to the impairment caused by the bulky triglyceride molecule, with cis double bonds at the fatty acid residues, which hinders favourable interactions with casein at the droplet interface. Such behaviour was found to be mostly independent of $\mathrm{pH}$ and ionic strength.

Emulsions with decane as the oil phase, stabilized either by $\beta$-casein or sodium caseinate, were solid-like systems with very intense viscoelasticity, good stability and macroscopic homogeneity. The contribution of their elastic compliance, $J$, surpassed $90 \%$ in almost all cases. A very distinct behaviour was verified for the casein/ vegetable oil (triglyceride-rich)/water emulsions, with systems exhibiting quasi-Newtonian flows.

Emulsion particle morphology and size distribution, within the optical microscopy scale, did not allow inferences regarding possible correlations between structural features and distinct rheological behaviour. We assume that relevant distinctions are likely to be present at the emulsion droplet interface, unapproachable by optical microscopy, rather than on aspects related to particle size or shape. Also, distinct dynamic populations were reckoned to be present suggesting the formation of dynamic complexes under flow.

Flow activation energies varied within the range of noncovalent interactions such as hydrogen bonds and van der Waals for all samples, confirming the transient character of interparticle interactions. The existence of distinct "internal" droplet interactions has been verified.

\section{Acknowledgments}

Authors acknowledge financial support from FAPESP and CNPq for this work. E.N. Figueiredo is grateful to $\mathrm{CNPq} / \mathrm{PIBIC}$ and FAPESP for the grant of undergraduate scholarships. J.A.G Arêas is recipient of a research scholarship granted by CNPq. The authors acknowledge support from M. A. da Silva (IQ-USP) in the rheological measurements and are grateful to L. A. Gioielli (FCF-USP) for access to the optical microscopy facilities. 


\section{References}

1. Dalgleish, D. G.; West, S. J.; Hallet, F. R.; Colloids Surf., A 1997, 123/124, 145

2. Dickinson, E.; Int. Dairy J. 1999, 9, 305.

3. Walstra, P.; Jenness, R.; Dairy Chemistry and Physics, Wiley: New York, 1988.

4. Holt, C.; de Kruif, C. G.; Tuinier R.; Timmins P. A.; Colloids Surf., A 2003, 213, 275.

5. Farrell Jr.; H. M.; Qi, P. X.; Wickham, E. D.; Unruh, J. J.; J. Prot. Chem. 2002, 21, 307.

6. Arêas, J. A. G.; Cassiano, M. M.; Glaubitz, C.; Watts, A.; Magnetic Resonance in Food Science - A View to the Future. Webb, Belton, Gil, Delgadillo, eds.; Royal Chemical Society: London, 2001.

7. Cassiano, M. M.; Arêas, J. A. G.; J. Mol. Struct. (THEOCHEM) 2001, 539, 279.

8. Cassiano M. M.; Arêas J. A. G.; J. Dairy Sci. 2003, 86, 3876.

9. Van Hekken, D. L.; Strange, E. D.; J. Dairy Sci. 1993, 76, 3384.

10. Husband, F. A.; Wilde, P. J.; Mackie, A. R.; Garrood. M. J.; J. Colloid Interface Sci. 1997, 195, 77.

11. Caessens, P. W. J. R., Gruppen, H.; Slangen, C. J.; Visser, S.; Vorangen, A. G. J.; J. Agric. Food Chem. 1999, 47, 1856.
12. Rampon, V.; Brossard, C.; Mouhous-Riou, N.; Bousseau, B.; Llamas, G.; Genot C.; Adv. Colloid Interface Sci. 2004, 108/109, 87.

13. Bylaite, E.; Nylander, T.; Venskutonis, R.; Jönsson, B.; Colloids Surf., B 2001, 20, 327.

14. Garti, N.; Slavin, Y.; Aserin, A.; Food Hydrocolloids 1999, 13, 127

15. Agboola, S. O.; Dalgleish, D. G.; Food Sci. Technol-Lebensm.Wissensch. Technol. 1996, 29, 425.

16. Dickinson, E.; Williams, A.; Colloids Surf., A 1994, 88, 317.

17. Hemar, Y.; Horne, D. S.; Colloids Surf., B 1999, 12, 239

18. Barnes, H. A.; Hutton, J. F.; Walters, K.; An Introduction to Rheology, Elsevier: Amsterdam, 1989.

19. Fisher, L. R.; Mitchell, E. E.; Parker, N. S.; J. Food Sci. 1985 , $50,1201$.

20. Courthaudon, J.-L.; Dickinson, E.; Christie, W. W.; J. Agric. Food Chem. 1991, 39, 1365.

21. Dickinson, E.; Tanai, S.; Food Hydrocolloids 1992, 6, 163.

22. Dickinson, E.; Iveson, G.; Food Hydrocolloids 1993, 6, 533.

23. Hemar Y.; Horne D. S.; Langmuir 2000, 16 , 3050.

24. Barros, C. N.; Arêas, E. P. G.; Figueiredo, E. N.; Arêas J. A. G.; Colloids Surf., B 2006, 48, 119.

Received: November 23, 2007

Web Release Date: August 13, 2008

FAPESP helped in meeting the publication costs of this article. 